\title{
1 The Route of Urbanisation in China from an International Perspective
}

Xiaolu Wang ${ }^{1}$

\section{Introduction}

This chapter examines China's urban development strategy from an international perspective. There are ongoing debates as to whether the Government's plan for urbanisation should focus on the development of small and medium size cities and towns, or whether instead China should allow, and encourage, more large cities to emerge to accommodate the large scale of urbanisation. This has been a highly controversial issue in China and raises the more general issue of whether, and to what extent, the Chinese Government should intervene in the process of urbanisation, which has hitherto been driven largely by market forces. A cross-country econometric analysis shows that the concentration ratio of the population (defined as the percentage of the population living in mega-cities - that is, cities with a population of 1 million and above) is determined by the level of economic development, the urbanisation ratio, population density, transport conditions, and the geographic location of the country. From this perspective, the concentration ratio in China is shown to be far below the international convention. To follow international common practice, China's concentration ratio should be lifted up by 17 percentage points (from the 2007 level) by 2030. This means that an additional 273 million people will transfer to megacities in China between now and then.

The next section provides some background information on the past route of China's urbanisation, and reviews the relevant literature. This is followed by an empirical study using cross-country data to examine the rationality of China's population concentration ratio, and a prediction for China's concentration ratio in the future, on the basis of international experience. Policy implications are discussed in the concluding section.

\section{Background}

During the 60 years since the 1949 revolution, the urbanisation process in China can be divided into three phases. In the first phase of central planning, urbanisation in China was extremely slow, especially compared with its rapid industrialisation. During the 26 years from 1952 to 1978, the industrial share in gross domestic product (GDP) increased by 27 percentage points - from 17.6 per cent to 44.4 per cent. During the same period, however, the urbanisation ratio (urban population as a proportion of the total) increased by only 5 percentage points - from 12.5 per cent to 17.9 per cent. This was abnormal 
compared with urbanisation in other industrialising countries, resulting mainly from the government policy of sacrificing urbanisation in order to maximise industrial investment for its industrialisation strategy.

This policy significantly accelerated the process of industrialisation in the early years of this period. Its negative impacts, however, gradually dominated. Efficiency in the industrial sector became very low and there were many failures in investment programs in industry; service sectors remained underdeveloped; the urban-rural income gap became larger and larger; and there was serious underemployment in the rural sector. These were due largely to the underdevelopment of the urban economy. Things went to the extreme in the 1960s and 1970s when many factories were built in mountain areas, far away from cities, and suffered from the difficulties of procuring inputs and subsequently transporting production to distant markets.

The second phase of urbanisation was from 1979 to the late 1990s - that is, the early economic reform period. During this period, the old policy of restricting urban development was partially abandoned and replaced with a policy that aimed to 'strictly restrict the scale expansion of large cities, reasonably develop medium and small cities, and actively develop small towns'. This policy freed limitations on the development of medium and small cities and towns, and gradually loosened restrictions on rural-urban labour migration. Together with the systematic transition from a centrally planned economy to a market economy, this led to rapid urbanisation as well as rapid economic growth. During the 20 years from 1979 to 1998, the urbanisation ratio increased by 15 percentage points - from 17.9 per cent to 33.3 per cent. Compared with the earlier period, in the second phase, the speed of urbanisation was several times higher.

During this period, the total number of cities in China expanded dramatically from 193 to 668, of which the number of medium and small cities (medium cities are defined as those having an urban population between 200000 and 500 000) increased from 153 to 583 - that is, a 281 per cent increase. In contrast, the number of large cities increased by 89 per cent-from 45 to 85 . In this period, the average city population decreased from roughly 400000 to 300000 .

During this period, the number of small towns increased even more rapidly than the number of medium and small cities - from some 2000 to 18 000. This was a result pushed by government administrative power. The total population living in towns, however, increased by 60 per cent - from roughly 100 million to 160 million-implying a dramatic drop in the average population size of towns. This indicates that, despite the policy bias in their direction, small towns lacked the attractiveness for population concentration and the capital investment for further developing themselves.

The third phase of urbanisation commenced in the late 1990s, when the policy restriction on the development of large cities was abandoned and replaced with a new policy called 'harmonising the development of large, medium and small cities and small towns'. Rural-urban labour migration, instead of being merely allowed, was encouraged in some senses (although still restricted in certain aspects such as through the household registration system). During this phase, the process of urbanisation further accelerated, with the urbanisation ratio increasing by 13 percentage points - from 33.3 per cent in 1998 
to 46.6 per cent in 2009. In particular, the number of mega-cities increased from 81 to 124 , whereas the number of smaller cities decreased from 587 to 530. This suggests that, in contrast with the Government's preference for smaller cities in the earlier periods, market forces prefer mega-cities to smaller ones.

Despite these changes, some recent studies indicate that the average size of Chinese cities is still too small (for example, Gill and Kharas 2007; Henderson 2007). This is at least partially due to continuing restrictions within the urban household registration system and the exclusion of migrant workers from urban social security and public service systems.

The problem also comes from frequent policy vacillations. For instance, an official document of the Central Committee of the Chinese Communist Party on the Twelfth FiveYear Plan, published in October 2010, called for 'taking medium and small cities and towns as a priority' in urban development, and asked local governments to loosen the limitations of household registration in these smaller cities and towns. While this made some progress in terms of urbanisation, it appears to be a partial copy of the earlier restrictive policy against large cities.

Attempts to avoid the development of large cities have a few possible explanations. One of these comes from the fear of 'large city disease'. This relates to assessments of the negative externalities of large cities, as discussed further below. Another comes from a misunderstanding on land use in different cities. It is often seen in official statements that, with consideration of land scarcity in China, priority should be given to the development of small cities and towns. Chinese statistics show, however, that per capita land use in small cities and towns is actually far larger than in large cities.

Table 18.1 shows that, in 2007, urban built areas had only 73 sq m per person in larger cities, $94 \mathrm{sq} \mathrm{m}$ per person in smaller cities, $121 \mathrm{sq} \mathrm{m}$ per person in county towns, and $183 \mathrm{sq}$ m per person in ordinary towns. The last column of Table 18.1 shows the ratios of per capita urban areas, taking that area in cities with a population size of 4 million or above as 1 , showing that per capita urban land areas in smaller cities decrease rapidly with city size.

Table 18.1 Per capita land use in different sized cities and towns

\begin{tabular}{|l|c|c|c|}
\hline $\begin{array}{l}\text { City size } \\
\text { (million persons) }\end{array}$ & $\begin{array}{c}\text { Per capita urban } \\
\text { built area (sq m) }\end{array}$ & $\begin{array}{c}\text { Per capita urban } \\
\text { area (sq m) }\end{array}$ & $\begin{array}{c}\text { Ratio in per capita urban area } \\
(\geq 4 \text { million cities }=1)\end{array}$ \\
\hline$\geq 4$ & 76 & 888 & 1.0 \\
\hline$\geq 2$ & 83 & 1061 & 1.2 \\
\hline $1-2$ & 62 & 1499 & 1.7 \\
\hline $0.5-1$ & 75 & 2280 & 2.6 \\
\hline$<0.5$ & 94 & 5596 & 6.3 \\
\hline County town & 121 &.. &.. \\
\hline Ordinary town & 183 &.. &.. \\
\hline
\end{tabular}


According to urban economics theories, cities - especially large ones-have positive externalities stemming from agglomeration effects, which come from more efficient trade and lower transport costs led by population concentration and larger sized markets for goods, inputs and production factors; more efficient use of land and infrastructure; industrial cluster effects; stronger spill-overs of information, knowledge and technology; and higher productivity resulting from better developed service sectors.

Large cities also have negative externalities due to transport congestion, environmental pollution, higher living costs and the deterioration of living conditions of residents, which all result from high population density and industrial concentration. Therefore, a key issue is how to optimise city scale taking these positive and negative externalities into account.

In an earlier study, Wang and Xia (1999) set up an econometric model, using panel data for more than 600 Chinese cities for the period between 1989 and 1996, to estimate the positive and negative externalities of cities. They derived a positive and marginally diminishing externality function and a negative and marginally increasing externality function. Between these two externality curves, they find an inverted-U shaped net return to scale of cities within a large range of city sizes. Of different scaled cities, those with an urban population between 1 and 4 million are found to be optimal, with net returns to city scale at 17-19 per cent of the total value added of these cities. For cities below the population size of 100000 people, no net return was found.

Based on this result and Chinese city statistics, the authors argued that there were too few large cities in China, and that the Government's policy of restricting the development of large cities and encouraging the development of small towns had led to efficiency losses, and should be replaced. They suggested an active policy for the Government to improve the provision of public services and to extend the social security system to cover ruralurban migrant workers and enable them to settle in cities. They also suggested that the Government improve infrastructure conditions in a limited number of medium-sized cities with better market environments and natural endowments, to enable them to grow into larger cities, rather than spending government resources investing in too many small cities and towns.

$\mathrm{Au}$ and Henderson (2006) also use Chinese city-level data and econometric models to find an inverted-U shaped agglomeration effect of cities along with changing city scales. They estimate that, given an output ratio between the manufacturing and service sectors of 1 , the optimal employment size of cities (where value added per worker is maximised) is 1.17 million (implying a total population of about 2.3 million). Where the manufacturingservice ratio is 0.6 , the optimal employment size is 1.44 million (implying a total population of 2.8 million). Thus, the findings from the two studies - that is, Au and Henderson (2006) and Wang and Xia (1999) - are basically consistent. ${ }^{2}$

Henderson (2007) also suggests that if the sizes of Chinese prefecture-level cities doubled, their labour productivity could increase by 20-35 per cent. His calculations, however, seem to be based on gross returns and do not deduct the negative externalities.

Both these studies were based on data for individual cities, and were thus unable to investigate the issue of spatial interactions among different Chinese cities. ${ }^{3}$ With consideration of these interactions, I assume that different-sized cities (and towns) in an economy form a 
system, and therefore there is no single solution for optimal city size. While questions of optimal city size remain interesting and important, we shift our attention here to study the role of large cities in a country, and what are the influential factors on this issue - rather than focusing on optimal size per se.

\section{An empirical analysis from an international perspective: the role of mega-cities}

Urbanisation has been a non-exceptional phenomenon experienced by all industrialised countries during their development process. Different countries have shared many common features in their urbanisation process, including an increasing concentration of the population in large cities that is driven by the agglomeration effects.

Meanwhile, there have also been differences in urbanisation patterns, in terms of pace and extent, city scale and the spatial distribution of cities. These differences will be determined by a range of country-specific economic, demographic, geographic and social conditions, including the level of economic development, population density, the geographic location and natural endowments of a country, transport conditions, and government policies.

This section draws on cross-country data to examine the range of factors that influence national-level concentration ratios, which provide an indication of how city scale changes. The concentration ratio is measured as the proportion of the population in a nation living in cities with a population size of 1 million and above (mega-cities), and is used as an indicator of city scale. Data are from the World Bank $(2008,2009)$. The hypotheses to be tested include the following.

1. To benefit from city-level agglomeration effects, a larger part of the population in a nation gradually gathers in mega-cities during the process of economic development; therefore the level of economic development has a positive effect on the concentration ratio.

2. Without achieving a certain level of urbanisation, mega-cities can hardly develop themselves; thus, the urbanisation ratio (population share in urban areas) also has a positive effect on the concentration ratio. ${ }^{4}$

3. Higher population density means land resources are more scarce and therefore more costly; therefore the market mechanism will naturally lead to a higher concentration of the population (that is, in mega-cities) to save land resources. A lower population density (and thus a broader population distribution) will, however, have greater transport needs, which might also result in a higher concentration of the population in order to reduce transport costs. These two effects work in opposite directions, so this study tests which effect dominates.

4. Given the same population density, better transport conditions can reduce the necessity for population concentration. This is because, as travelling becomes easier, people can live in smaller cities near large central cities, so that they can enjoy lower living costs, an easier life in smaller cities, and better services provided in central cities at the same time. Thus, transport conditions should have a negative effect on the concentration ratio. 
5. Greater income inequality leads to a higher concentration ratio. This is because the greater the income inequality, the larger will be the income gap between mega-cities and small cities and towns, and this makes mega-cities more attractive.

6. Different geographic locations, which reflect different natural environmental and human ecological conditions, can have positive or negative effects on the concentration ratio.

Finally, government policies - that is, whether governments prefer large or small cities and how they use various policy measures to affect the urbanisation process - can also affect the concentration ratio. Country-specific information is, however, not available for this hypothesis, and is therefore not tested here.

To test the above hypotheses 1-6, a linear model is set as follows ${ }^{5}$ (Equation 18.1).

Equation 18.1

$$
m=c+a_{1} y+a_{2} u+a_{3} d+a_{4} r+a_{5} g+a_{6} a o n+a_{7} e u+\varepsilon
$$

In Equation 18.1, $m$ is the concentration ratio; $y$ is per capita gross national income (GNI) in a purchasing power parity (PPP) measure, indicating the level of economic development; $u$ is the urbanisation ratio - that is, the proportion of urban population in the country; $d$ is the population density, measured by the number of persons per square kilometre of the territory; $r$ is a road density variable to present the transport conditions - that is, kilometres of highway and railway length per $100 \mathrm{sq} \mathrm{km}$ of the territory, where railway length is converted into highway equivalent by multiplying by a conversion factor of 14.7, which was derived from Chinese empirical data; $g$ is the Gini coefficient for income inequality (or consumption inequality where income data are unavailable); aon is a regional dummy for North and South America, Oceania and North-East Asia; and eu is a regional dummy for European countries. African and the remaining Asian countries are taken as reference countries. Countries were grouped according to similarities that were found in preliminary regressions using more specific dummy variables.

Cross-country data for 2007 from the World Bank (2008, 2009) are used (where 2007 data are unavailable, 2005 or 2006 data are used instead). Lower-income countries (below US $\$ 2500$ per person, PPP) are considered to be not representative enough in terms of urban development, and small countries (with populations below 4 million, or with an area less than $20000 \mathrm{sq} \mathrm{km}$ ) are considered to be naturally restricted in their city-scale options. These two types of countries are therefore excluded from the data set. Countries with incomplete data are also dropped. There are 56 countries in the remaining sample.

Table 18.2 shows the robust regression results. Most estimates are statistically significant. Due to the low significance of the Gini coefficient in a preliminary regression, it is omitted from the model. Further investigations find that the fitted concentration ratios and the actual ones are close, with an average error of 2 percentage points. This indicates the satisfactory fitness of Equation 18.1. 
Table 18.2 Determinants of the concentration ratio: regression results

\begin{tabular}{|l|l|l|}
\hline & Coefficient & t-ratio (robust) \\
\hline$y$ & $5.03 E-06$ & $5.21^{* *}$ \\
\hline$u$ & 0.1561 & $2.12^{*}$ \\
\hline$d$ & $2.67 \mathrm{E}-04$ & $2.31^{*}$ \\
\hline$r$ & $-4.39 \mathrm{E}-04$ & $-3.16^{* *}$ \\
\hline aon & 0.1221 & $3.51^{* *}$ \\
\hline eu & -0.03525 & -0.87 \\
\hline Constant & 0.04194 & 0.94 \\
\hline Samples & 56 & \\
\hline$R^{2}$ & 0.6824 & \\
\hline
\end{tabular}

* significant at the 5 per cent level

** significant at the 1 per cent level

Source: Author's own estimation

As expected, per capita GNI, the urbanisation ratio and population density all have positive and significant impacts on the concentration ratio, while road density has a negative and significant effect. The regional dummies imply that the concentration ratios of American, Oceanian and North-East Asian countries are 12 percentage points higher than in African and other Asian countries, all other conditions being equal. The European dummy variable has a negative but insignificant coefficient.

Based on the coefficients obtained from the regression based on Equation 18.1, we can predict China's current and future concentration ratio assuming that international convention is followed - that is, given China's level of development and other relevant factors, the concentration ratio China would have according to the international average when other conditions are equal. Other assumptions for the prediction are as follows.

a. Per capita GNI (PPP\$ in 2009 prices) in China will grow at an annual rate of 7 per cent between 2010 and 2020 to achieve $\$ 13682$ in 2020, and then by 6.5 per cent between 2021 and 2030, to achieve $\$ 25682$ in $2030 .^{6}$

b. The urbanisation ratio will continue to increase by 1 percentage point per annum during the period 2010-20, to achieve 59.7 per cent by 2020, and then by 0.8 percentage points during the period 2021-30, to achieve 67.7 per cent by 2030 (during the period 2001-10, the urbanisation ratio was lifted by 1.35 percentage points per annum).

c. China's population will grow at 0.5 per cent per annum during the $2010-20$ period to achieve 1.41 billion, and then by 0.3 per cent per annum during the 2021-30 period to achieve 1.45 billion, to increase the population density from 139 (2009 figure) to 147 persons/sq $\mathrm{km}$ by 2020, and then to 151 persons/sq $\mathrm{km}$ by $2030 .{ }^{7}$ As a reference, from 2000 to 2010, the actual annual population growth rate was 0.6 per cent.

d. Road density will double during the $2007-20$ period to achieve $99 \mathrm{~km} / 100 \mathrm{sq}$ $\mathrm{km}$, and further increase by 50 per cent during the second period to achieve $148 \mathrm{~km} / 100 \mathrm{sq} \mathrm{km}$. By way of comparison, road density in 2007 in the United States 
was $107 \mathrm{~km} / 100 \mathrm{sq} \mathrm{km}$, and it was 417 km/100 sq km in Japan (World Bank 2009). Road density in China doubled between 1999 and 2007.

The result of the prediction for China's concentration ratio is shown in Table 18.3. The values for each determinant in the first three columns are their true values (for 2009) and assumed values (for 2020 and 2030), and the data in the last three columns are the predicted effects on the concentration ratio, in percentage points. The bottom row presents the sum of these effects - that is, the predicted concentration ratios for the corresponding years.

As shown in Table 18.3, the actual concentration ratio in China in 2007 was 20.4 per cent ${ }^{8}$ (that is, 20.4 per cent of the total population in China lived in mega-cities), which is below the world average (24.6 per cent in 2005). The predicted ratio for China in 2009, based on the international average given the level of development and other conditions, is 28.8 per cent. This indicates that the proportion of the Chinese population living in mega-cities is significantly below international common practice, implying a serious underdevelopment of mega-cities in China from an international perspective. This result is consistent with some comparative studies using international data (for example, Gill and Kharas 2007) and the empirical studies based on the Chinese city-level data (Au and Henderson 2006; Wang and Xia 1999) — which all indicates that average city size in China is too small. While the empirical model does not test for it, these results suggest that this might well be the result of restrictive government policies on the development of large cities or on rural-urban migration.

Based on the prediction shown in Table 18.3, to follow international common practice, 32 per cent of the Chinese population will live in mega-cities by 2020, and this proportion will reach 37 per cent by 2030 . These concentration ratios are significantly higher than the present level in China, although they are still below present levels in the United States and Japan (at 43 per cent and 48 per cent, respectively). Dividing the 17 percentage point increases in the concentration ratio-from 2007 to 2030-into contributions from each different factor reveals that economic growth, urbanisation and population growth in China will contribute 9.6, 3 and 0.3 percentage points, respectively, to the increasing concentration ratio, while the improvement in transport conditions will reduce the concentration ratio by 4.3 percentage points. These four factors will together contribute 8.6 percentage points. The remaining unexplained 8.4 percentage point increase in the concentration ratio will, very likely, be attributed to policy adjustments that abandon restrictions on large-city development and rural-urban migration.

Based on these predictions, to achieve the concentration ratios of 32.2 per cent in 2020 and 37.5 per cent in 2030, the population living in Chinese mega-cities will need to reach 454 million people by 2020, and 543 million by 2030. This means an increase of 273 million people in mega-cities by 2030 from the 2007 level. 


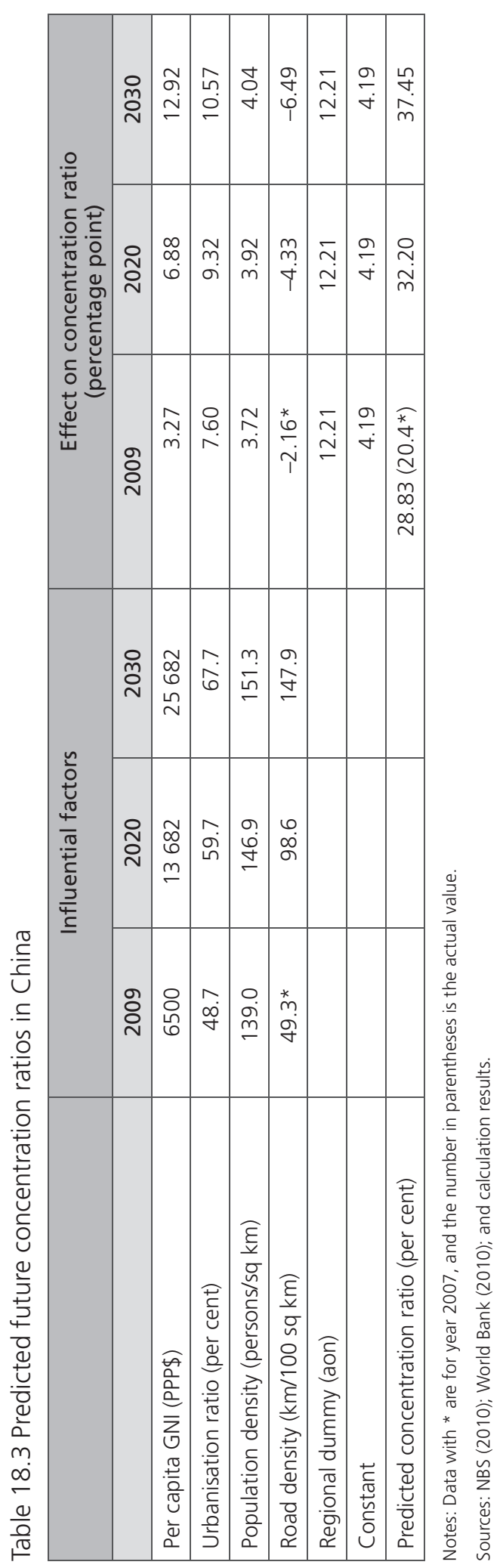


An often-seen argument in China is that further increases in the population living in mega-cities will make these cities overcrowded. This will not necessarily be true, however, because the average population size of mega-cities could remain unchanged as long as the number of mega-cities grows rapidly enough. For this to be the case, the number of megacities would need to double - from the current number of 124 to 250. More realistically, both the average population of current mega-cities and the number of mega-cities will need to increase over time.

Most of these new mega-cities will develop from the current medium-sized cities, or even small cities. Over time, a few new super economic and population centres might emerge, besides the current Yangtze River Delta, Pearl River Delta and Beijing-TianjinHebei areas - for instance, the Chongqing-Chengdu area and the Wuhan-Changsha area.

Considering that the current concentration ratio is too low, even a positive policy adjustment might not lead to the predicted concentration ratio of 32 per cent by 2020 . Assuming that by 2020 it can reach 30 per cent, this still implies a large population increase in mega-cities of 154 million people. For this to materialise, future policy adjustment will need to remove remaining restrictions that have hindered the urbanisation process to a certain extent, and the expansion of mega-city populations in particular. With consideration of the effects of both aggregate demand growth and efficiency increases, the development of mega-cities will continue to be a major engine of economic growth in the coming decades (Au and Henderson 2006; Wang and Xia 1999).

\section{Conclusions}

This chapter analysed the determinants of China's national-level concentration ratiothat is, the ratio of the population living in mega-cities - from an international perspective. The cross-country analysis indicated that this ratio is positively affected by each country's level of economic development, degree of urbanisation and population density, while being negatively affected by transport infrastructure. Geographic location was shown to have either a positive or a negative effect on the concentration ratio.

Based on these results, drawn from international experience, the author suggests that a more rational concentration ratio in China should be close to 29 per cent in 2009-about 8 percentage points higher than its actual level. This indicates an underdevelopment of mega-cities in China - likely due to policy restrictions in the earlier period, the unreformed urban household registration system and the incompletion of social security systems in urban areas, which exclude the majority of rural-urban migrant workers from coverage.

Assuming that future policy adjustment will continue to lead China's urbanisation process to follow international convention in the coming decades, it is predicted that China's concentration ratio will reach 37 per cent in 2030. This means that the population living in mega-cities will grow from the current 270 million to 543 million - a 273 million increase. In other words, the urbanising population in the coming two decades will concentrate mainly in mega-cities. This does not, however, necessarily imply a further expansion of the size of current mega-cities, but rather suggests the need for more mega-cities in China. Because of the positive agglomeration effect of mega-cities, this development in the coming 
two decades will become a strong engine for China's economic growth, and might bring China into the high-income-country group. To achieve this, however, numerous policy adjustments will be necessary.

First, government policy preferences towards the development of small cities and towns should be replaced with a more neutral urbanisation policy. Some of the preferential policies enjoyed by a small number of selected large cities (especially provincial and capital cities) should also be removed. Population and resources flowing into large cities, led by market forces, are usually indicators of improvement in resource allocation, and should not be redirected by government restrictions.

Second, the urban household registration system, which hinders rural-urban migrant workers from receiving coverage under the urban social security and public services systems, should be reformed. The provision of public services should be equalised among migrants and original urban residents.

Third, the role of government in urban development should be, in general, complementary with market forces. Meanwhile, because of the positive and negative externalities of urban economies, the Government still has an important role to play. For instance, further development of large cities relies heavily on urban planning and infrastructure improvements. In these areas, governments should continue to play active roles.

Fourth, due to city-based negative externalities, some mega-cities might become oversized, and this is unlikely to be automatically corrected by market forces. International experience shows that, once a city becomes oversized, its transport conditions and living environment deteriorate, and both living costs and production costs become high. Cities such as Shanghai and Beijing are approaching a population size of 20 million, and the trend of their expansion is continuing. To prevent the unlimited expansion of these super megacities, it might be useful to promote the development of second-tier cities and small cities in the surrounding areas, so that the migration pressure towards these super mega-cities can be alleviated.

For instance, there is only one mega-city within $120 \mathrm{~km}$ of Beijing, and there are only two mega-cities within $130 \mathrm{~km}$ of Shanghai. In contrast, there are six mega-cities in the Pearl River Delta region, within an $80 \mathrm{~km}$ radius. This could explain why no city in this area exceeds a population of 10 million. Therefore, more mega-cities might be a better solution for the problem of oversized super mega-cities, particularly compared with administrative measures that simply restrict migration towards those super mega-cities.

Fifth, as indicated by the results of empirical analysis in this chapter, a better road network - especially better intercity transport systems - might be another effective measure to alleviate the migration pressure towards oversized, or soon-to-be oversized, super megacities. This is because better transport conditions can enable people to live in nearby smaller cities and, at the same time, to enjoy the better services provided in the super cities. 
In general, a market-friendly urbanisation policy framework, together with carefully designed government measures to deal with the positive and negative externalities of the urban economies, will accelerate the urbanisation process in China and improve the efficiency of the urban economies at the same time, thereby playing a critical role in sustaining China's long-run development.

\section{Bibliography}

$\mathrm{Au}, \mathrm{C}$. and Henderson, V. 2006, 'Are Chinese cities too small?', Review of Economic Studies, vol. 73, no. 2, pp. 549-76.

Dobkins, L. H. and Ioannides, Y. M. 2001, 'Spatial interactions among US cities: 1900-1990', Regional Science and Urban Economics, vol. 31, pp. 701-31.

Gill, I. and Kharas, H. 2007, An East Asian Renaissance: Ideas for economic growth, The World Bank, Washington, DC.

Henderson, J. V. 1987, 'General equilibrium modeling of systems of cities', in E. S. Mills (ed.), Handbook of Regional and Urban Economics. Volume 2, Elsevier, Amsterdam, pp. 927-56.

Henderson, J. V. 2007, Urbanization in China: Policy issues and options, China Economic Research and Advisory Programme.

Maddison, A. 2007, Chinese Economic Performance in the Long Run, (Second edition), Development Centre of the Organisation for Economic Cooperation and Development, Paris.

National Bureau of Statistics (NBS) various years, China Statistical Yearbook, China Statistics Press, Beijing.

National Bureau of Statistics (NBS) 2008, China City Statistical Yearbook, China Statistics Press, Beijing.

National Bureau of Statistics (NBS) 2010, China Statistical Yearbook 2010, China Statistics Press, Beijing.

National Bureau of Statistics (NBS) 2011, Press release on major figures of the 2010 National Population Census, National Bureau of Statistics, Beijing, <http://www.stats.gov.cn/tjfx/ jdfx/t20110428_402722521.htm>

O'Sullivan, A. 2000, Urban Economics, (Fourth edition), McGraw-Hill, New York.

United Nations Population Division (UNPD) 2008, World Population Prospects: The 2008 revision, United Nations Population Division, New York, <http://data.un.org/Data.aspx $? \mathrm{q}=$ China $\& \mathrm{~d}=$ PopDiv $\& \mathrm{f}=$ variableID $\% 3$ al $2 \% 3 \mathrm{bcrID} \% 3 \mathrm{al} 56 \% 2 \mathrm{c} 948>$

Wang, X. and Xia, X. 1999, 'Promoting economic growth by optimizing urban size', [In Chinese], Economic Research Journal, no. 9 (September).

World Bank various years, World Development Report, The World Bank, Washington, DC.

World Bank 2008, World Development Indicators, The World Bank, Washington, DC. 
World Bank 2009, World Development Report, The World Bank, Washington, DC.

World Bank 2010, World Development Report, The World Bank, Washington, DC.

\section{Endnotes}

1. The author thanks Jane Golley for her very helpful comments and language revisions.

2. Au and Henderson suggest that their study is the first one to use econometrical tools to estimate the agglomeration effect of cities. This seems to be a result of information insufficiency due to language barriers (Wang and Xia's 1999 paper is published in Chinese).

3. For references, see Dobkins and Ioannides (2001); for the case of US cities, see also Henderson (1987); and O'Sullivan (2000).

4. One could argue that the concentration ratio can also affect both the level of economic development and the urbanisation ratio - thus, there exists a reverse-causality problem. These effects work, however, basically in the long run - for example, changes in the concentration ratio in the short run might affect economic growth and efficiency marginally, but will have little impact on the current level of development of a country. Thus, in the current cross-section regression, the author treats both the level of economic development and the urbanisation ratio as exogenous variables for simplicity.

5. An alternative equation with inclusion of the square term of the explanatory variables was tested for possible non-linearity, but estimates of all the square terms were insignificant, and calculation shows better fitness of the original equation than the alternative one. The results of the latter are therefore not reported.

6. Angus Maddison (2007) estimated that GDP growth in China in a PPP measure was 6.6 per cent per annum from 1978 to 2003. Economic growth further accelerated in China, however, during the post-2003 period. In addition, the 2005 economic censuses in China found serious underreporting in services sector output in previous official statistics, and this indicates underreporting of the economic growth rate in that period.

7. These assumptions are based on the United Nations' population forecast - slightly modified by the author with reference to the results of the recent Chinese population census (see UNPD 2008; and NBS 2011).

8. This number excludes the population in county-level cities (smaller cities) with a population above 1 million, because they usually include a large number of rural people, and therefore their urban population size in statistics is overstated. 